\title{
$O$ ponto de partida para uma teoria das narrativas jornalísticas
}

\section{Magali Moser}

Jornalista, doutoranda no Programa de Pós-Graduação em Jornalismo na Universidade Federal de Santa Catarina, bolsista pela Fapesc.

E-mail:magali.moser@ gmail.com

${ }^{1}$ Além do livro mais recente, também podem ser citados: Narratologia: teoria e análise da narrativa jornalística (MOTTA, 2005a); o capítulo Análise Pragmática da Narrativa Jornalística, publicado no livro Metodologia da Pesquisa em Jornalismo (LAGO; BENETTI, 2007); e o artigo homônimo apresentado no Congresso Nacional da Intercom de 2005 (MOTTA, 2005b).
SOSTER, Demétrio de Azeredo; PICCININ, Fabiana Quatrin (Orgs). Narrativas midiáticas contemporâneas: perspectivas epistemológicas. Santa Cruz do Sul: Catarse, 2017.

Estudar o jornalismo como uma narrativa pode nos levar a uma teoria específica? Os estudos das narrativas jornalísticas adquirem a autonomia de um campo particular? As perguntas surgem a partir da leitura de Narrativas Midiáticas Contemporâneas: perspectivas epistemológicas, organizado por Demétrio de Azeredo Soster e Fabiana Quatrin Piccinin, lançado em 2017, pela editora Catarse. O jornalismo visto como uma narrativa permite a análise das escolhas assumidas pelo narrador - e suas consequentes motivações (intencionalidades, interesses) - na apresentação dos fatos. Não é tarefa fácil, no entanto, assumir esta perspectiva, alerta o professor e pesquisador Luiz Gonzaga Motta (UnB), no prefácio da obra. Conceitos como objetividade e veracidade tentam apagar as intenções e mediação de quem narra no campo jornalístico. O olhar narrativo requer admitir subjetividade para um formato que se espera objetivo. Não há como fugir de indagações necessárias: quem é, afinal, o narrador no jornalismo? Como se dão as relações de poder entre fonte, empresa, editores e repórteres? Os questionamentos perpassam não só o prefácio, mas também as discussões propostas nos 23 artigos reunidos na coletânea.

A escolha por Luiz Gonzaga Motta para prefaciar a obra não se dá por acaso. Ele aparece repetidamente citado nos artigos da coleção. É uma das principais referências teóricas no Brasil que sustentam a perspectiva da narrativa, principalmente com o livro Análise Crítica da Narrativa, de 2013르. Ele próprio assina um dos capítulos que compõem a obra, onde apresenta mais interrogações do que respostas ou a promessa de "um novo caminho epistemológico", como ele próprio define. Não é preciso chegar ao final da leitura das 313 páginas para se convencer de que o estudo da narrativa jornalística não só pode ser trilhado por diferentes caminhos e óticas, como também se constitui uma das formas de se pensar, a partir dele, uma teoria específica. Motta insiste nesta hipótese. Para o autor, a objetividade é um recurso intencional com a pretensão de garantir "efeitos de verdade", assegurando credibilidade aos veículos e promovendo a aproximação com o público, que os vê geralmente como legítimos porta-vozes da realidade.

A busca por trazer novas perspectivas e problematizações sobre o narrar atravessa a obra. Em 2015, a Rede de Narrativas Midiáticas (Renami) foi criada com a intenção de reunir pesquisadores acerca das complexidades apresentadas pelo estudo das narrativas midiáticas. A interpretação da contemporaneidade através de suas narrativas traz consigo desafios implacáveis, considerando o jornalismo como narrativa do tempo presente. O livro demonstra algumas possibilidades 
ao percorrer uma diversidade de narrativas midiáticas, num conjunto abrangente, heterogêneo e multifacetado. Divide-se em quatro fragmentos: Perspectivas reflexivas, Visadas aplicadas, Narrativas do eu e Outros olhares. O esforço observado em cada uma das partes se concentra em fornecer subsídios para interpretar as narrativas jornalísticas, em quais formatos estiverem.

O telejornal, o jornal impresso, o livro-reportagem, as redes sociais... e os diferentes gêneros jornalísticos, o informativo (com a notícia, unidade básica de informação no jornalismo, e a reportagem), opinativo (redes sociais) ou interpretativo (biografias, perfis, livros-reportagem) não escapam das análises desenvolvidas na obra. Há, no entanto, uma ausência de reflexão mais detida acerca das narrativas do radiojornalismo. Apesar de o rádio ter se reinventado com as múltiplas possibilidades de comunicação e pertencer aos meios de comunicação tradicionais, analisados de modo geral na obra, entendo que mereceria pelo menos um capítulo mais detalhado, assim como se fez com outros meios. A palavra radiojornalismo aparece uma única vez no livro, numa nota de rodapé. Certamente, a lacuna se dá não em razão da falta de referências de pesquisa nesta área, considerando o fortalecimento de grupos de estudo sobre a temática, a exemplo do que ocorre na Intercom, com o GP de Rádio e Mídia Sonora. Ainda que este não tenha sido o objetivo da publicação, como foi pormenorizado o estudo de determinados formatos e veículos, uma abordagem mais aprofundada das narrativas no rádio fez falta. De todo modo, as reflexões apresentadas convergem para uma necessidade de reavaliar a função social do jornalismo e a impossibilidade de uma mediação sem interferências.

A partir da comunicação, o ser humano dá sentido às suas relações. O desejo e a necessidade pela informação acompanham a humanidade no processo de humanização, assim como o ato de narrar - seria intrinsecamente cultural, portanto, culturalmente inventado, e não dado da natureza. Mas o contar também alcança aspecto mítico quando constrói personagens como heróis. Apesar de ter semelhanças com a narrativa literária, a narrativa jornalística diferencia-se pela capacidade de contribuir para a construção social da realidade. Assim como o real pode se fazer presente na literatura, o fantástico ou literário também podem estar na notícia. Nos dois âmbitos - ficcional ou jornalístico - nenhuma narrativa é ingênua, ressalva Motta. A escolha por contar prevê a pretensão de seduzir, envolver, provocar uma reação, ou "efeitos de sentido". Também por discutir esses temas, esse é um livro pertinente, pois alarga uma visão da narrativa como simples sinônimo da realidade, tal como muitos imaginam ser. A enunciação narrativa pressupõe intenção e uma inevitável sucessão temporal. Todo ato de fala requer argumentação e carga ideológica.

Sim, porque a suposta neutralidade jornalística não se sustenta se analisarmos a simples seleção e apresentação como se dão as notícias nos jornais diários. A escolha por um assunto de capa em detrimento de outro, a opção de uma manchete no lugar de outra revelam procedimentos relacionados a uma determinada posição assumida. Os estudos e referenciais sobre a narrativa como perspectiva teórica e metodológica para o estudo do jornalismo estão contextualizados no artigo Jornalismo e narrativa: aspectos do estado da arte das pesquisas no Brasil, assinado por Miriam Redin de Quadros, Juliana Motta e Lara Nasi. Elas analisam textos publicados entre 2012 e 2016, nos anais de três dos principais congressos nacionais da área da Comunicação, promovidos pela Associação Nacional dos Programas de Pós-Graduação em Comunicação (Compós), pela Sociedade Brasileira de Estudos Interdisciplinares da Comunicação (Intercom) e pela Associação Brasileira de Pesquisadores em Jornalismo (SBPJor).

Ao observarem como a narrativa tem sido abordada nos estudos sobre jornalismo, identificam os principais autores e metodologias citados nessas discussões 
teóricas. No quesito sustentação teórica, Luiz Gonzaga Motta (UnB), o filósofo francês Paul Ricoeur, Cremilda Medina (USP) e Muniz Sodré (UFRJ) são os mais referenciados. Na perspectiva metodológica, Motta é lembrado novamente, desta vez como o autor mais citado. $\mathrm{O}$ estudo também reforçou o predomínio de pesquisas empíricas em relação às teóricas quando se estuda as narrativas no jornalismo. A narratividade do jornalismo não se limita à análise das textualidades, observam as autoras, "mas as considera inseridas em uma historicidade, dotadas de vinculações sociais e como resultado de modos de produção institucionalizados" (QUADROS et al, 2017, p.36). Elas se referem a todo o contexto de produção e recepção das narrativas jornalísticas, compreendendo o estudo da narrativa como uma forma de permitir a interpretação do jornalismo.

O artigo de autoria do professor Motta, publicado na coletânea intitula-se, Análise pragmática da narrativa: teoria da narrativa como teoria da ação comunicativa. A compreensão de Motta parte do entendimento de que a narrativa é um espaço permanente de disputas. Sempre há tentativas no sentido de tornar uma versão "mais verdadeira" ou "mais legítima" que a outra. O autor defende com ênfase novamente a ideia de que a narratologia deveria desvincular-se da teoria literária para assumir um procedimento multidisciplinar (MOTTA, 2013). A argumentação ganha força no atual cenário midiático, marcado por uma forte disputa de narrativas e pela difusão de tecnologias capazes de garantir ao público o protagonismo do contar. Inspirado em Ricoeur, Motta conclui que a teoria da narrativa se torna uma teoria da ação comunicativa: "Seu uso deixa de atender apenas à crítica literária ou estética para tornar-se uma metodologia crítica dos atos narrativos" (MOTTA, 2017, p. 52).

A importância da incorporação do contexto e das circunstâncias (fatores extralinguísticos) aos procedimentos de análise é um elemento que aproxima as discussões realizadas por diferentes autores da obra. De modo mais explícito ou nas entrelinhas, esta defesa estabelece um ponto comum de diálogo, com a precaução de que ainda faltam métodos e técnicas para associar o estudo das narrativas ao seu contexto de produção. Como refletem Monica Martinez e Mara Rovida num dos capítulos. "Toda narrativa está impregnada de um movimento que a antecede, pois há sempre um caminho prévio percorrido, claramente refletido ou não, que evidencia o tempo e o espaço nos quais o autor está mergulhado" (MARTINEZ; ROVIDA, 2017, p. 189). Mas, há também o reconhecimento de que, garantir subsídios para a análise das influências contextuais, esbarra em desafios metodológicos como a delimitação do que caracteriza o contexto. Para este problema, uma das propostas possíveis seria uma teoria ampliada de círculos dêiticos (MOTTA, 2017, p. 58).

As reflexões sugeridas pelos artigos evocam inovações e criatividades intrínsecas ao ato de contar. Esta constatação se dá pela ampla diversidade de temas, abordagens e leituras que contemplam a narrativa em suas múltiplas formas e suportes. Tensionamentos em torno de conceitos da produção jornalística, como notícia e função social; papel da imprensa na esfera pública; relações entre tempo social e acontecimento; função discursiva das fontes no jornalismo literário e as instâncias autor e narrador na reportagem são algumas das temáticas levantadas na primeira parte da obra. A segunda concentra reflexões como aproximações entre a micro história e o jornalismo nos chamados "livros de repórteres"; paralelos entre jornalismo e cidade como construção de significados; narrativas visuais na grande reportagem e as narrativas do repórter Ernest Hemingway. No terceiro momento, assumem destaque a constituição temporal do gênero biografia jornalística; temporalidades das narrativas dos diários íntimos; semelhanças entre os processos narrativos jornalístico, psicológico e etnográfico; o estético e o ideológico nas estratégias narrativas das histórias de vida; particularidades da construção narrativa e da memória em livros-reportagem e o fenômeno do narrar-se no 
contexto das redes sociais. Por fim, a última seção reúne olhares para o futuro. Nela, são discutidas questões ligadas às novas interações e imersões em plataformas midiáticas multissensoriais; o narrar de modo transcriativo; as narrativas em produções televisivas brasileiras; o uso do recurso da audiodescrição no "jornalismo acessível” e a midiatização das narrativas de viagem realizada de bicicleta.

Dos livros-reportagem ao ambiente digital. O caráter narrativo percorre as narrativas desde a instituição da reportagem ilustrada na Revista O Cruzeiro, nos anos 1940, por exemplo, ao formato multimídia, com as narrativas centradas em torno do eu, no Facebook - para citar duas temáticas apresentadas no livro. Não apenas pela multiplicidade de olhares, mas, sobretudo pelo esforço em destrinchar uma instigação central no jornalismo - a análise de suas narrativas, com todas as implicações e limitações decorrentes desse processo - ouso afirmar que a obra se faz obrigatória para quem busca compreender o jornalismo como campo de conhecimento. Delimitar suas bases teóricas e a clareza de seu objeto de estudo parece-nos condição fundamental no campo de estudos do jornalismo. Não há dúvidas de que o empenho em compreender como analisar as suas narrativas é um passo considerável rumo à teorização sobre o fazer jornalístico. O livro dá uma resposta afirmativa à pergunta "Rumo a uma teoria da narrativa jornalística?" lançada no prefácio. Sim, é tempo de o jornalismo se repensar.

\section{REFERÊNCIAS:}

MOTTA, Luiz Gonzaga. Análise crítica da narrativa. Brasília: Editora Universidade de Brasília, 2013.

Análise pragmática da narrativa jornalística. In: LAGO, C.; BENETTI, M. (Orgs.). Metodologia de pesquisa em jornalismo. Petrópolis: Ed. Vozes, 2007.

Narratologia: análise da narrativa jornalística. Brasília: Casa das Musas, 2005a.

A Análise Pragmática da Narrativa Jornalística. In: CONGRESSO BRASILEIRO DE CIÊNCIAS DA COMUNICAÇÃO. 28., 2005, Rio de Janeiro. Anais... Manaus: Intercom, 2005b. Disponível em: <http://www.intercom.org.br/papers/ nacionais/2005/resumos/R2419-1.pdf >. Acesso em: 18 mar 2018.

SOSTER, Demétrio de Azeredo; PICCININ, Fabiana Quatrin (Orgs.). Narrativas midiáticas contemporâneas: perspectivas epistemológicas. Santa Cruz do Sul: Catarse, 2017. Disponível em: <http://editoracatarse.com.br/site/wp-content/ uploads/2017/10/Narrativas midi\%C3\%A1ticas contempor\%C3\%A2neas perspectivas epistemol\%C3\%B3gicas.pdf >. Acesso em: 18 mar 2018. 